\title{
Functional screening of aldehyde decarbonylases for long-chain alkane production by Saccharomyces cerevisiae
} CrossMark

\author{
Min-Kyoung Kang ${ }^{1 \dagger}$, Yongjin J. Zhou ${ }^{1,2,5 \dagger}{ }^{+}$Nicolaas A. Buijs ${ }^{1,6}$ and Jens Nielsen ${ }^{1,2,3,4^{*}}$
}

\begin{abstract}
Background: Low catalytic activities of pathway enzymes are often a limitation when using microbial based chemical production. Recent studies indicated that the enzyme activity of aldehyde decarbonylase (AD) is a critical bottleneck for alkane biosynthesis in Saccharomyces cerevisiae. We therefore performed functional screening to identify efficient ADs that can improve alkane production by S. cerevisiae.

Results: A comparative study of ADs originated from a plant, insects, and cyanobacteria were conducted in $S$. cerevisiae. As a result, expression of aldehyde deformylating oxygenases (ADOs), which are cyanobacterial ADs, from Synechococcus elongatus and Crocosphaera watsonii converted fatty aldehydes to corresponding $C_{n-1}$ alkanes and alkenes. The CWADO showed the highest alkane titer $\left(0.13 \mathrm{mg} / \mathrm{L} / \mathrm{OD}_{600}\right)$ and the lowest fatty alcohol production $\left(0.55 \mathrm{mg} / \mathrm{L} / \mathrm{OD}_{600}\right)$. However, no measurable alkanes and alkenes were detected in other AD expressed yeast strains. Dynamic expression of SeADO and CWADO under GAL promoters increased alkane production to $0.20 \mathrm{mg} / \mathrm{L} / \mathrm{OD}_{600}$ and no fatty alcohols, with even number chain lengths from C8 to C14, were detected in the cells.

Conclusions: We demonstrated in vivo enzyme activities of ADs by displaying profiles of alkanes and fatty alcohols in S. cerevisiae. Among the AD enzymes evaluated, cyanobacteria ADOs were found to be suitable for alkane biosynthesis in S. cerevisiae. This work will be helpful to decide an AD candidate for alkane biosynthesis in S. cerevisiae and it will provide useful information for further investigation of AD enzymes with improved activities.
\end{abstract}

Keywords: Metabolic engineering, Saccharomyces cerevisiae, Alkane biosynthesis, Aldehyde decarbonylase, Biofuels

\section{Background}

Global warming and depletion of fossil fuels are two urgent matters. Fossil fuels are finite energy resources, but the world energy demand has been increasing along with economic development and population growth. Moreover, increase in carbon dioxide emissions have caused the global temperature to rise resulting in dramatic environmental changes. Therefore, there has been growing interest in sustainable production of biofuels and bio-based chemicals using microorganisms, so called cell factories. Advances in metabolic engineering and

\footnotetext{
*Correspondence: nielsenj@chalmers.se

${ }^{\dagger}$ Min-Kyoung Kang and Yongjin J. Zhou equally contributed to this work

1 Department of Biology and Biological Engineering, Chalmers University

of Technology, Kemivägen 10, 41296 Gothenburg, Sweden

Full list of author information is available at the end of the article
}

synthetic biology enables the production of bio-based chemicals using microbial cell factories [1-5].

One of the most important microbial cell factories, Saccharomyces cerevisiae is generally recognized as safe (GRAS) and, it is an extremely well-characterized and tractable organism. Because of its robustness and tolerance towards various stress conditions, it has been intensively used to produce several advanced biofuels and chemicals [6-9].

Alkanes are indispensable chemicals in our daily lives. As major components of current petroleum fuels, the chain lengths of alkanes determine their applications, such as gas $(\mathrm{C} 1-\mathrm{C} 4)$, gasoline $(\mathrm{C} 4-\mathrm{C} 9)$, jet fuel $(\mathrm{C} 8-$ C16), diesel (C10-18), and lubricants (C16-C30) [10]. In nature, a variety of organisms synthesize alkanes to protect them against threatening environmental conditions, 
or to sustain growth [11-13]. However, the alkane production level from natural producers is very low and the alkane formulas are not suitable to replace current petroleum-based alkanes [1, 2]. In addition, current alkane needs are only fulfilled after the challenging and costly cracking processes of crude petroleum. Therefore, many efforts have been made to engineer microorganisms to produce desirable types of alkanes. Several alkane biosynthetic routes have been discovered and various enzymes are available to synthesize alkanes in heterologous hosts $[14,15]$. To date, three major precursors, fatty acyl-ACP (or CoA), fatty acids, and fatty aldehydes have been utilized to demonstrate alkane production in engineered microorganisms $[14,15]$. Aldehyde decarbonylases (ADs), which were discovered in plants, insects, and cyanobacteria, can convert fatty aldehydes to the corresponding $\mathrm{C}_{\mathrm{n}-1}$ alkanes by co-producing carbon monoxide $(\mathrm{CO})$, carbon dioxide $\left(\mathrm{CO}_{2}\right)$, or formate, respectively. In engineered microbial strains, expression of ADs from a plant (Arabidopsis CER1), an insect (Drosophila melanogaster CYP4G1), and various species of cyanobacteria (ADOs) displayed long-chain alkane products $[12,13,16$, 17]. However, the low enzyme activities of cyanobacteria ADs have been noticed and only allow for low alkane titers in S. cerevisiae [17-20]. To date, no direct comparative study of ADs from different origins for alkane biosynthesis has been carried out, so we performed a functional screening of different ADs to identify applicable enzyme candidates that can increase alkane production in S. cerevisiae. We constructed AD expressing yeast strains and presented the cell metabolite profiles of alkanes and fatty alcohols from each construct. In light of these results, we suggested the most efficient AD enzyme and proposed a strategy to enhance alkane production. As the mechanisms of $\mathrm{AD}$ enzymes are not clearly elucidated, our study explored to develop ideal AD enzymes for alkane biosynthesis in yeast cell factories. We anticipate the strategy described here will provide a feasible strategy to functional screening of other AD enzymes for various microbial cell factories.

\section{Results}

\section{Construction of alkane biosynthetic pathways}

In our previous study, the fatty acid biosynthetic pathway was engineered to supply sufficient fatty aldehydes in S. cerevisiae [18]. Here we used the engineered strain YJZ60 from this study as the background strain. The strain was optimized to accumulate fatty aldehydes in cells by deleting reversible reactions (POX1 and HFD1) and expressing carboxylic acid reductase $(C A R)$. One of the competing enzymes, alcohol dehydrogenase, Adh5, was deleted to reduce fatty alcohol accumulation (Fig. 1). In addition, the FNR/Fd reducing systems were expressed

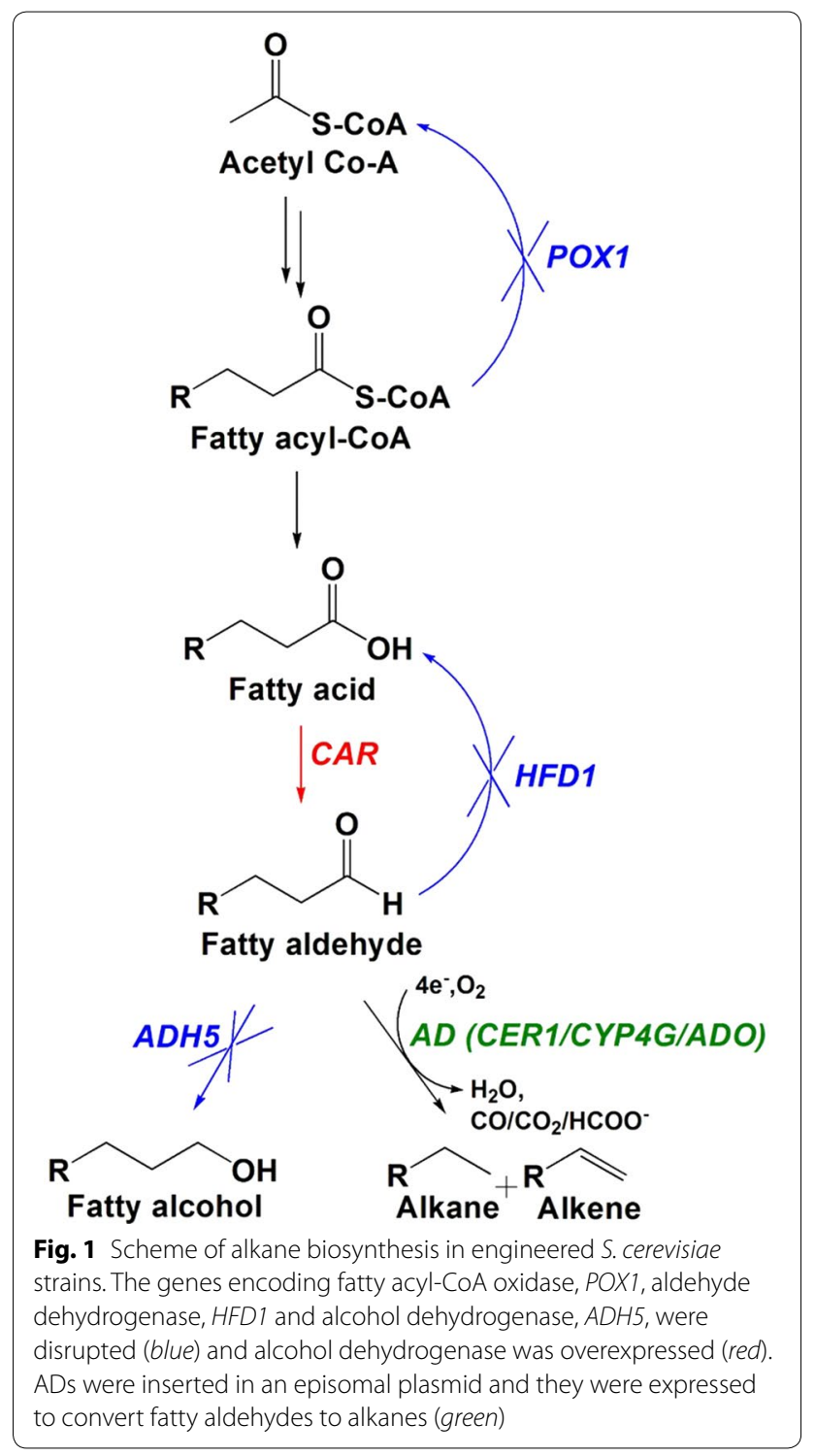

to supply sufficient electrons. Figure 1 and Table 1 summarizes information of YJZ60. To enable S. cerevisiae to convert the synthesized aldehydes to alkanes, we expressed various ADs by using the episomal plasmid pYX212 in the background strain YJZ60. We introduced three different types of ADs, the ECERIFERUM1 (CER1) from Arabidopsis plant [16, 21], insect cytochrome p450s (CYP4G1 and CYP4G2) from D. melanogaster and house fly [12], and cyanobacteria aldehyde deformylating oxidases (ADOs) from S. elongatus [17, 18], Crocosphaera watsonii, Thermosynechococcus elongatus, and Cyanothece sp. PCC 7425 [22] (Table 1; Additional file 1: Figure $\mathrm{S} 1$ ). All $\mathrm{AD}$ candidates were selected by literature reviews and preliminary data. Codon-optimized ADO and CER1 genes were expressed under the control of 
Table 1 Strains and plasmids used in this study

\begin{tabular}{|c|c|c|}
\hline Name & Description & Reference \\
\hline \multicolumn{3}{|l|}{ Plasmids } \\
\hline pYX212 & $2 \mu \mathrm{m}, \mathrm{AmpR}, \mathrm{URA3}, \mathrm{TPIp}, \mathrm{pYX} 212 \mathrm{t}$ & R\&D systems \\
\hline pAlkane78 & pYX212-(TPIp-Mdb5-FBA1t-CYC1t-MdCPR-TDH3p-tHXT7P-CYP4G1-pYX212t) & This study \\
\hline pAlkane8 & pYX212-(TPIp-Mdb5-FBA1t-CYC1t-MdCPR-TDH3p-tHXT7P-CYP4G2-pYX212t) & This study \\
\hline pAlkane71 & pYX212-(eTDH3p-CER1-Syn27t-pYX212t) & This study \\
\hline pAlkane67 & pYX212-(eTDH3p-SeADO-pYX212t) & {$[17]$} \\
\hline pAlkane83 & pYX212-(eTDH3p-CwADO-pYX212t) & This study \\
\hline pAlkane84 & pYX212-(eTDH3p-TeADO-pYX212t) & This study \\
\hline pAlkane85 & pYX212-(eTDH3p-CyADO-pYX212t) & This study \\
\hline pAlkane86 & pYX212-(CYC1t-CwADO-Gal10p-Gal1p-SeADO-pYX212t) & This study \\
\hline \multicolumn{3}{|l|}{ Strains } \\
\hline $\mathrm{DH} 5 \mathrm{a}$ & $\mathrm{F}^{-}$(80d lacZ M15) (lacZYA-argF) U169 hsdR17( $\left.\mathrm{r}^{-} \mathrm{m}^{+}\right)$recA1 endA1 relA1 deoR96 & \\
\hline YJZ60 & $\begin{array}{l}\text { MATa MAL2-8c SUC2 his3 } \triangle 1 \text { ura3-52 hfd1 } \triangle \text { pox1 } \triangle \text { Gal80 } \triangle: \text { SeFNR + SeFd adh5 } \triangle::(T P I p-M m C A R- \\
\text { FBA1t) + (PGK1p-ECFNR-CYC1t) + (TEF1p-EcFD-TDH2t) + (tHXT7p-npgA-ADH5t) }\end{array}$ & {$[17]$} \\
\hline Con & YJZ60 strain harboring pYX212 & This study \\
\hline CYP4G1 & YJZ60 strain harboring pAlkane78 & This study \\
\hline CYP4G2 & YJZ60 strain harboring pAlkane8 & This study \\
\hline CER1 & YJZ60 strain harboring pAlkane71 & This study \\
\hline SeADO & YJZ60 strain harboring pAlkane67 & This study \\
\hline CWADO & YJZ60 strain harboring pAlkane83 & This study \\
\hline TeADO & YJZ60 strain harboring pAlkane84 & This study \\
\hline CyADO & YJZ60 strain harboring pAlkane85 & This study \\
\hline CSADO & YJZ60 strain harboring pAlkane86 & This study \\
\hline
\end{tabular}

the enhanced TDH3 promoter [23], while CYP4G1 and CYP4G2 were expressed under the control of the truncated HXT7 promoter, tHXT7p [24], yeast S. cerevisiae allowing constitutive expression independent of extracellular glucose levels. Additional file 1: Figure S1 provides brief features of the used gene expression modules. In the CSADO strain, C. watsoni and S. elongatus ADOs were co-expressed under the control of the GAL1 and GAL1O promoters, respectively (Table 1; Additional file 1: Figure S1) to alleviate the growth inhibition by separating cell growth and gene expression.

\section{Evaluation of ADs for alkane biosynthesis in S. cerevisiae} After the introduction of ADs in YJZ60, we carried out functional evaluation of three different types of ADs (CER1, CYP4G, and ADO). Among all the AD constructs tested, only two cyanobacterial ADOs from $S$. elongatus (SeADO) and C. watsonii (CwADO) produced longchain alkanes and alkenes. Expression of ADOs from $S$. elongatus and C. watsonii, reached 0.11 and $0.13 \mathrm{mg} / \mathrm{L} /$ $\mathrm{OD}_{600}$ of total alkanes and alkenes, respectively, with different odd chain lengths from $\mathrm{C} 11$ to $\mathrm{C} 17$ (Fig. 2a; Additional file 1: Figure S2a). The major compounds in both strains were pentadecane $(\mathrm{C} 15)$ and 7-pentadecene (C15:1) (Additional file 1: Figure S2a).
We found accumulation of fatty alcohols in all the engineered strains (Fig. 2b). This is consistent with previous observations that fatty alcohols are produced as significant by-products in engineered $S$. cerevisiae expressing alkane biosynthesis, and might be caused by endogenous aldehyde reductases (ALRs) and alcohol dehydrogenases (ADHs) $[17,18]$.The control strain Con without AD had the highest fatty alcohol accumulation $\left(1.71 \mathrm{mg} / \mathrm{L} / \mathrm{OD}_{600}\right.$, Fig. 2) with even number chain lengths from $\mathrm{C} 8$ to $\mathrm{C} 18$ and the CwADO strain produced the lowest amount of fatty alcohols $\left(0.55 \mathrm{mg} / \mathrm{L} / \mathrm{OD}_{600}\right)$ in the cells (Additional file 1: Figure $\mathrm{S} 2$ ). Other AD expressing strains produced fatty alcohol levels in between these strains, i.e. TeADO: $1.29 \mathrm{mg} / \mathrm{L} / \mathrm{OD}_{600}, \mathrm{CER} 1: 1.44 \mathrm{mg} / \mathrm{L} / \mathrm{OD}_{600}$, CYP4G1: $1.33 \mathrm{mg} / \mathrm{L} / \mathrm{OD}_{600}$, and CYP4G2: $0.97 \mathrm{mg} / \mathrm{L} / \mathrm{OD}_{600}$ (Fig. 2b). The alkane production is much lower than the decrease in fatty alcohol accumulation when the CwADO and SeADO strains are compared with the control strain (Fig. 2a, b), and suggests that the functional ADs have a high binding affinity for fatty aldehydes, but low catalytic efficiency for alkane biosynthesis.

Though the CwADO strain had the highest alkane production and the lowest fatty alcohol production, this strain showed very poor growth $\left(\mathrm{OD}_{600}\right.$ of 3.5 at $\left.72 \mathrm{~h}\right)$ compared with the SeADO $\left(\mathrm{OD}_{600}\right.$ of 6.1 at $\left.72 \mathrm{~h}\right)$ and 

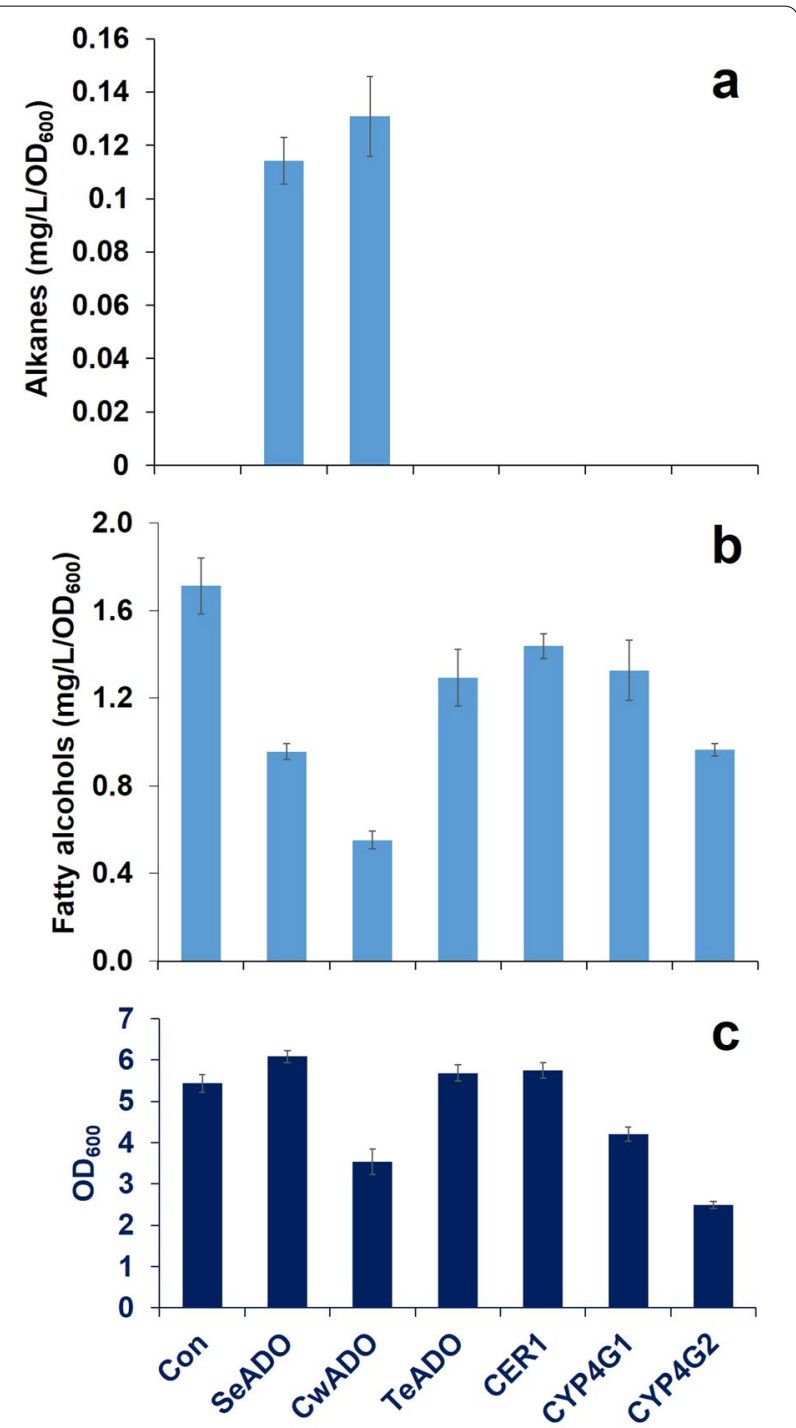

Fig. 2 Comparison of alkane and fatty alcohol production by different $\mathrm{AD}$ expression in engineered S. cerevisiae strains. Alkane (a) and fatty alcohol (b) titers, and cell growth (c) were demonstrated from each engineered strain after $72 \mathrm{~h}$ culture in minimal media. All data represent the mean values and standard deviations from at least triplicate cultures

control strains $\left(\mathrm{OD}_{600}\right.$ of 5.4 at $\left.72 \mathrm{~h}\right)$, which might be attributed to toxicity (Fig. 2c). For this reason, the total amount of alkanes and alkenes produced by the CwADO strain $(0.53 \mathrm{mg} / \mathrm{L})$ is lower than with the SeADO strain $(0.76 \mathrm{mg} / \mathrm{L})$ (Fig. 2a). Improving cell growth of the CwADO expressing strain could therefore potentially further increase alkane production.

\section{Enhancement of alkane production}

In order to relieve the toxicity of expressing CwADO in the cell, we dynamically expressed CwADO by using the GAL1 promoter (GAL1p) in combination with the
GAL80 deletion. It has been found that the GAL1 promoter has very low expression in the glucose phase due to Mig1 repression, but is strongly expressed after glucose consumption in a GAL80 deletion strain [25]. Hereby CwADO expression could be separated from cell growth, as has been previously applied for improving isoprenoid production by yeast [26]. To further increase alkane biosynthesis, we co-expressed SeADO under the control of the GAL10 promoter (Gal10p). The resulting strain CSADO had significantly higher specific alkane production of $0.20 \mathrm{mg} / \mathrm{L} / \mathrm{OD}_{600}$, (Fig. 3a) which was 35 and $45 \%$ higher compared with the CwADO and SeADO strains, respectively (Fig. 3a). We even detected undecane (C11) in the CSADO strain (Additional file 1: Figure S3a). Furthermore, CSADO had $62 \%$ higher biomass $\left(\mathrm{OD}_{600}\right.$ of 5.7 at $72 \mathrm{~h}$, Fig. 3c) than the strain CwADO expressed under the TDH3 promoter (Fig. 3c), which indicated that the dynamic control strategy relieved the toxicity of $\mathrm{CwADO}$ expression. As a benefit to improved cell growth, the alkane titer reached $1.14 \mathrm{mg} / \mathrm{L}$, which is higher than with our previous strain A6 that had systematic pathway optimization [18]. This suggests that functional AD screening with dynamic expression could be an efficient strategy for enhancing alkane production in yeast.

\section{Discussion}

In this study, long-chain alkane biosynthesis has been constructed via decarbonylation of fatty aldehydes by AD enzymes in S. cerevisiae [12, 16-18]. However, efficient incorporating of heterologous metabolic pathways into S. cerevisiae is challenging and strong endogenous ALRs/ ADHs compete with the intermediate fatty aldehydes [18]. Indeed, low catalytic efficiency of ADs has been referred to as a critical bottleneck in alkane biosynthesis in engineered S. cerevisiae strains [17-19]. Therefore, it is worthwhile to screen efficient AD enzymes to provide a rationale enzyme for the improvement of alkane biosynthesis in microbial cell factories. To meet this goal, we carried out functional screening of ADs from different origins by comparing alkane and fatty alcohol accumulation in the cells. ADs were introduced using episomal plasmids and expressed in an engineered yeast strain, YJZ60, which provides fatty aldehydes as substrates for alkane biosynthesis. Of all the strains we tested, cyanobacteria ADOs (SeADO and CwADO) synthesized alkanes more efficiently than the CER1 and CYP4G enzymes (Fig. 2a). Even though very-long-chain (VLC) alkane production by CER1 and CYP4G1 have been reported in yeast strains $[12,16]$, we only found a reduction of fatty alcohol accumulation, but no detectable amounts of alkanes were produced in our yeast strains. We assume substrate preferences of plant and insect ADs might explain this. In fact, plants and insects synthesize 

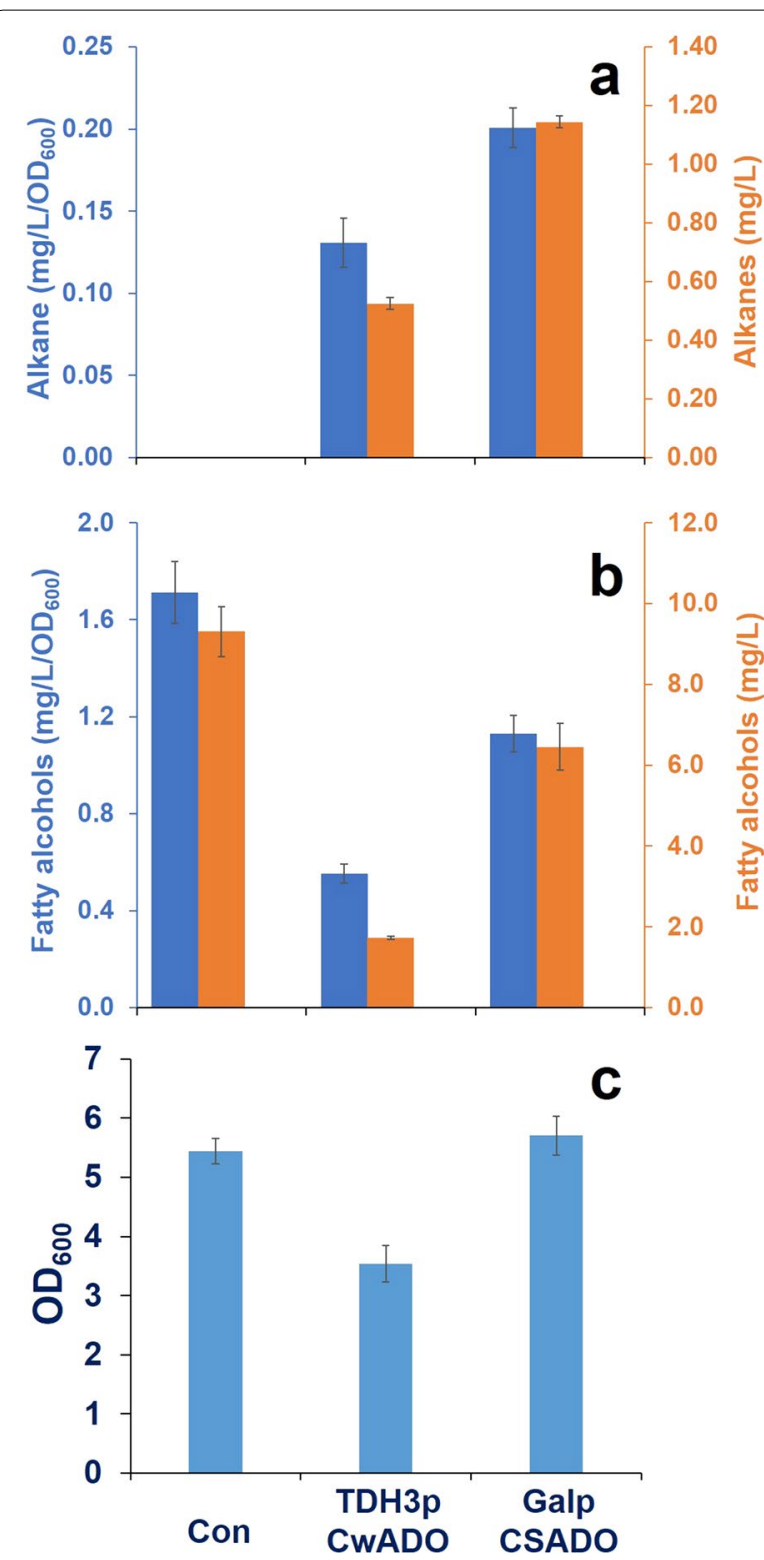

Fig. 3 Enhancement of alkane production. Production of alkanes (a) and fatty alcohols $(\mathbf{b})$, and two titer units (left blue $\mathrm{mg} / \mathrm{L} / \mathrm{OD}_{600}$, right orange $\mathrm{mg} / \mathrm{L}$ ) are used to display the level of metabolites. Cell growth of each strain is shown in (c). All data represent the mean values and standard deviations from at least triplicate cultures

VLC alkanes to form a wax layer and cuticular hydrocarbons, respectively, for environmental protection [27, 28]. Arabidopsis (CER1) synthesized VLC alkanes with the range of chain lengths being C27-C31 [16], and insect CYP4G family produces C23-C33 chain lengths VLC alkanes $[12,29,30]$. Through the distribution of fatty alcohol chain lengths (Additional file 1: Figure S2b), we predicted accumulation of fatty aldehydes with the even number of chain lengths, $\mathrm{C} 8-\mathrm{C} 18$ in our background strain, which might be unfavorable substrates for CER1 and CYP4Gs. Meanwhile, major alkane products synthesized by cyanobacteria ADOs are pentadecane (C15) and heptadecane (C17) [13], and both compounds were also major metabolites in our SeADO and CwADO yeast strains (Additional file 1: Figure S2a). Another presumable reason might be the environmental condition for proper function of the $\mathrm{AD}$ enzymes. The yeast cytosol may not be an optimized compartment for function of CER1 and CYP4Gs. To date, cyanobacteria ADO is the only group of $\mathrm{AD}$ enzymes, which have been demonstrated to have in vitro enzyme activity [31-33]. Plant origin CER1 is an endoplasmic reticulum membrane bound protein and CYP4G1 is localized in oenocytes [12]. The membrane protein expression often causes cell stresses and lower the biomass and expression. In addition, folding and solubility of eukaryotic membrane proteins is generally causing difficulties for performing kinetic studies [34], so no enzyme activity studies have been successfully conducted. Likewise, the membrane association in plant cells may cause problems for proper function of the enzyme in the yeast cytosol. Moreover, the relatively larger size of CER1 and CYP4Gs may cause problems with folding and expression. Moreover, alkane peaks in a GC-MS chromatogram cannot be detected if the $\mathrm{AD}$ enzyme has low and slow activity. Because inefficient aldehyde conversion to alkanes leads to high fatty alcohol formation, and the fatty alcohol peaks cover the alkane detection area further causing difficulties in detecting alkanes.

The CwADO enzyme was revealed as a better enzyme compared with the SeADO, but expression of CwADO caused poor growth and negatively affected the final titer of alkanes. Thus, we replaced the TDH3 promoter with a GAL1 promoter to control the gene expression, and we placed additional SeADO right after the GAL10 promoter to co-express CwADO and SeADO in an episomal plasmid (Additional file 1: Figure S1). In our previous work, expression of additional ADO from Nostoc punctiforme (SeADO-NpADO) resulted in a $5 \%$ increase in alkane titer $(0.82 \mathrm{mg} / \mathrm{L})$ compared with only expressing SeADO $(0.78 \mathrm{mg} / \mathrm{L})$ [18]. In the case of the CSADO strain (CwADOSeADO), co-expression of CwADO achieved a significant improvement in alkane titer by 33\% (SeADO: $0.76 \mathrm{mg} / \mathrm{L}$, CSADO: $1.14 \mathrm{mg} / \mathrm{L}$ ) (Figs. 2a, 3a) and surprisingly no fatty alcohols with even number chain lengths $\mathrm{C} 8-\mathrm{C} 14$ were detected (Additional file 1: Figure S3b). In addition, the chain lengths of alkanes were extended from C11 to C17 (Additional file 1: Figure S3a) and growth was greatly improved in the CSADO strain $\left(\mathrm{OD}_{600}\right.$ of 3.5 at $72 \mathrm{~h}$, Fig. 3c) compared with the CwADO strain $\left(\mathrm{OD}_{600}\right.$ of 5.7 at $72 \mathrm{~h}$, Fig. 3c). Even though the CSADO strain lead to increase in alkane production, it was still far from the industrial 
requirements and even below the alkane titer in engineered E. coli $(580.8 \mathrm{mg} / \mathrm{L})$ and cyanobacteria $(300 \mathrm{mg} / \mathrm{L})[13,35]$. Unlike $E$. coli platforms, even the same enzymes involved in alkane biosynthesis produced much smaller quantities of alkanes in S. cerevisiae strains. Expression of CER1 enzyme in E. coli achieved the highest alkane titer [35], and the ADO enzymes from T. elongatus, and Cyanothece sp. also produced high amount of alkanes in E. coli [13, 22]. However, even trace alkanes were not observed in our CER1, TeADO, and CyADO yeast strains for uncertain reasons. Similar to the $\mathrm{AD}$ enzymes, expression of OleT decarboxylase, a terminal alkene producing enzyme, resulted in much higher terminal alkene production in $E$. coli $(97.6 \mathrm{mg} / \mathrm{L})$ than in S. cerevisiae $(3.5 \mathrm{mg} / \mathrm{L})$ [14]. To explain the big differences in alkane titer between $E$. coli and S. cerevisiae, other facts should be considered beyond the poor catalytic efficiencies of alkane producing enzymes.

\section{Conclusion}

In this study, we examined the functional performance of ADs in engineered yeast strains. Based on the metabolite profiles of our engineered strains, we proposed advisable ADs and their applications to enhance alkane production in S. cerevisiae. Our study further provides a platform strain that can be used for screening ADs to be used for alkane production in yeast with the objective to develop a yeast cell factory that can be used for bio-based production of alkanes.

\section{Methods}

\section{Construction of plasmids and yeast strains}

Plasmids and strains used in this study are shown in Table 1. Plasmid construction was performed by the modular pathway engineering procedure as described by Zhou et al. [36]. DNA fragments for module construction were prepared by PCR amplification and each module was constructed by fusion PCR. PrimeSTAR was used for all the PCR processes, and primers used in this work were listed in Additional file 1: Table S1. Yeast transformation was conducted by LiAc/SS carrier DNA/PEG method [37], and constructed modules and linearized pYX212 plasmid backbone were used as DNA templates. To make yeast competent cells, the YJZ60 yeast strain was cultured at $30{ }^{\circ} \mathrm{C}$ and $200 \mathrm{rpm}$ in YPD media, and transformants were selected on synthetic defined (SD) agar plates, which contained $6.9 \mathrm{~g} / \mathrm{L}$ yeast nitrogen base without amino acids (Formedium, Hunstanton, UK), $0.77 \mathrm{~g} / \mathrm{L}$ synthetic complete supplement mixture without uracil (Formedium), $20 \mathrm{~g} / \mathrm{L}$ glucose (Merck Millipore) and $20 \mathrm{~g} / \mathrm{L}$ agar (Merck Millipore). After the colony selection, yeast plasmids were extracted and introduced into E. coli $\mathrm{DH} 5 \alpha$ competent cells to confirm the final plasmid constructs. E. coli colonies were selected on Lysogeny
Broth (LB) agar plate containing $100 \mu \mathrm{g} / \mathrm{mL}$ ampicillin, and they were confirmed by DNA sequencing.

\section{Alkane biosynthesis and extraction}

To produce alkanes, engineered S. cerevisiae strains were grown in $100 \mathrm{~mL}$ shake flasks containing $15 \mathrm{~mL}$ mineral media [38] plus $40 \mathrm{mg} / \mathrm{L}$ histidine and $30 \mathrm{~g} / \mathrm{L}$ glucose at $30^{\circ} \mathrm{C}$ and $200 \mathrm{rpm}$ for $72 \mathrm{~h}$. After the cultivation, $10 \mathrm{~mL}$ of cell cultures were harvested by centrifugation at $2000 \mathrm{~g}$ for $10 \mathrm{~min}$, and then cell pellets were dried for $48 \mathrm{~h}$ in a freeze-dryer. The dried cells were extracted by the method described by Khoomrung [39] by using $4 \mathrm{~mL}$ chloroform: methanol ( $\mathrm{v} / \mathrm{v} 2: 1)$ solution containing hexadecane $(0.5 \mu \mathrm{g} / \mathrm{mL})$ and pentadecanol $(0.01 \mathrm{mg} / \mathrm{mL})$ as internal standards. After centrifugal vacuum concentration, the final dried samples were dissolved in $200 \mu \mathrm{L}$ hexane.

\section{Metabolite analysis and quantification}

Alkanes and alkenes were analyzed by gas chromatography (Focus GC, ThermoFisher Scientific) equipped with a Zebron ZB-5MS GUARDIAN capillary column $(30 \mathrm{~m} \times 0.25 \mathrm{~mm} \times 0.25 \mathrm{~mm}$, Phenomenex, Torrance, CA, USA) and a DSQII mass spectrometer (Thermo Fisher Scientific, Waltham, MA, USA). The GC program for alkanes and alkenes was as follows: initial temperature of $50{ }^{\circ} \mathrm{C}$, hold for $5 \mathrm{~min}$; then ramp to $140{ }^{\circ} \mathrm{C}$ at a rate of $10^{\circ} \mathrm{C}$ per min and hold for $10 \mathrm{~min}$; ramp to $310^{\circ} \mathrm{C}$ at a rate of $15{ }^{\circ} \mathrm{C}$ per min and hold for 7 min. Fatty alcohols were quantitatively analyzed by GC-FID (Thermo Fisher Scientific, Waltham, MA, USA) equipped with a ZB-5MS GUARDIAN capillary column, and helium was used as carrier gas at a flow rate of $1 \mathrm{~mL} / \mathrm{min}$. GC program for fatty alcohol quantification was as follows: initial temperature of $45^{\circ} \mathrm{C}$ hold for $2 \mathrm{~min}$; then ramp to $220^{\circ} \mathrm{C}$ at a rate of $20^{\circ} \mathrm{C}$ per min and hold for $2 \mathrm{~min}$; ramp to $300{ }^{\circ} \mathrm{C}$ at a rate of $20^{\circ} \mathrm{C}$ per min and hold for $5 \mathrm{~min}$.

\section{Additional file}

Additional file 1: Figure S1. Scheme of plasmid constructs for alkane biosynthesis. PYX212 vector was used as a backbone to express ADs in engineered S. cerevisiae strains. Figure S2. Comparison of alkane and fatty alcohol production by different AD expression in engineered S. cerevisiae strains. Alkane (a) and fatty alcohol (b) titers were displayed with the information of chain-length distribution of each engineered strain. All data represent the mean values and standard deviations from at least triplicate cultures. Figure S3. Production of alkanes (a) and fatty alcohols (b) with the information of chain-length distribution in the CSADO strain. All data represent the mean values and standard deviations from at least triplicate cultures. Table S1. Primers used in this study.

\section{Abbreviations}

AD: aldehyde decarbonylase; ADH: alcohol dehydrogenase; ADO: aldehyde deformylating oxygenase; ALR: aldehyde reductase; CAR: carboxylic acid reductase; PDH: pyruvate dehydrogenase; VLC: very-long-chain. 


\section{Authors' contributions}

The experiments were designed by YJZ and MK. MK and YJZ carried out the strain construction. NA provided preliminary data for enzyme selection. MK performed the cultivation experiments, analyzed the results and drafted the manuscript. YJZ, NA and MK revised the manuscript. JN supervised the design, revised the manuscript and coordinated the study. All authors read and approved the final manuscript.

\section{Author details \\ ${ }^{1}$ Department of Biology and Biological Engineering, Chalmers University of Technology, Kemivägen 10, 41296 Gothenburg, Sweden. ${ }^{2}$ Novo Nordisk Foundation Center for Biosustainability, Chalmers University of Technology, 41296 Gothenburg, Sweden. ${ }^{3}$ Novo Nordisk Foundation Center for Bio- sustainability, Technical University of Denmark, Kogle allé, 2970 Hørsholm, Denmark. ${ }^{4}$ Science for Life Laboratory, Royal Institute of Technology, 17121 Solna, Sweden. ${ }^{5}$ Present Address: Division of Biotechnology, Dalian Institute of Chemical Physics, Chinese Academy of Sciences, Dalian 116023 , China. ${ }^{6}$ Present Address: Evolva Biotech, Lersø Parkalle, 40-42, 2100 Copenha- gen, Denmark.}

\section{Acknowledgements}

This work was financed by the Novo Nordisk Foundation, Vetenskapsrådet, FORMAS and the Knut and Alice Wallenberg Foundation.

\section{Competing interests}

The authors declare that they have no competing interests.

\section{Availability of data and materials}

All data generated or analysed during this study are included in this published article and its Additional file 1.

\section{Publisher's Note}

Springer Nature remains neutral with regard to jurisdictional claims in published maps and institutional affiliations.

Received: 25 January 2017 Accepted: 18 April 2017

Published online: 02 May 2017

\section{References}

1. Peralta-Yahya PP, Zhang F, Del Cardayre SB, Keasling JD. Microbial engineering for the production of advanced biofuels. Nature. 2012;488:320-8.

2. Pfleger BF, Gossing M, Nielsen J. Metabolic engineering strategies for microbial synthesis of oleochemicals. Metab Eng. 2015;29:1-11.

3. Chen Y, Nielsen J. Advances in metabolic pathway and strain engineering paving the way for sustainable production of chemical building blocks. Curr Opin Biotechnol. 2013;24:965-72.

4. Nielsen J, Keasling JD. Engineering cellular metabolism. Cell. 2016;164:1185-97.

5. Gustavsson M, Lee SY. Prospects of microbial cell factories developed through systems metabolic engineering. Microb Biotechnol. 2016;9:610-7.

6. Borodina I, Nielsen J. Advances in metabolic engineering of yeast Saccharomyces cerevisiae for production of chemicals. Biotechnol J. 2014;9:609-20.

7. Buijs NA, Siewers V, Nielsen J. Advanced biofuel production by the yeast Saccharomyces cerevisiae. Curr Opin Chem Biol. 2013;17:480-8.

8. Nielsen J, Larsson C, van Maris A, Pronk J. Metabolic engineering of yeast for production of fuels and chemicals. Curr Opin Biotechnol. 2013;24:398-404

9. Zhou YJ, Buijs NA, Siewers V, Nielsen J. Fatty acid-derived biofuels and chemicals production in Saccharomyces cerevisiae. Front Bioeng Biotechnol. 2014;2:32.

10. Wade L Jr. Organic chemistry. 6th ed. New Jersey: Pearson Prentice Hall; 2006

11. Post-Beittenmiller D. Biochemistry and molecular biology of wax production in plants. Annu Rev Plant Physiol Plant Mol Biol. 1996:47:405-30.
12. Qiu Y, Tittiger C, Wicker-Thomas C, Le Goff G, Young S, Wajnberg E, Fricaux T, Taquet N, Blomquist GJ, Feyereisen R. An insect-specific P450 oxidative decarbonylase for cuticular hydrocarbon biosynthesis. Proc Natl Acad Sci. 2012;109:14858-63.

13. Schirmer A, Rude MA, Li X, Popova E, del Cardayre SB. Microbial biosynthesis of alkanes. Science. 2010;329(5991):559-62.

14. Kang MK, Nielsen J. Biobased production of alkanes and alkenes through metabolic engineering of microorganisms. J Ind Microbiol Biotechnol. 2016;1-10. doi:10.1007/s10295-016-1814-y.

15. Herman NA, Zhang W. Enzymes for fatty acid-based hydrocarbon biosynthesis. Curr Opin Chem Biol. 2016;35:22-8.

16. Bernard A, Domergue F, Pascal S, Jetter R, Renne C, Faure J-D, Haslam RP, Napier JA, Lessire R, Joubès J. Reconstitution of plant alkane biosynthesis in yeast demonstrates that Arabidopsis ECERIFERUM1 and ECERIFERUM3 are core components of a very-long-chain alkane synthesis complex. Plant Cell. 2012;24:3106-18.

17. Buijs NA, Zhou YJ, Siewers V, Nielsen J. Long-chain alkane production by the yeast Saccharomyces cerevisiae. Biotechnol Bioeng. 2015;112:1275-9.

18. Zhou YJ, Buijs NA, Zhu Z, Qin J, Siewers V, Nielsen J. Production of fatty acid-derived oleochemicals and biofuels by synthetic yeast cell factories. Nat Commun. 2016;7:11709.

19. Marsh ENG, Waugh MW. Aldehyde decarbonylases: enigmatic enzymes of hydrocarbon biosynthesis. ACS Catal. 2013;3:2515-21.

20. Zhou YJ, Buijs NA, Zhu Z, Gomez DO, Boonsombuti A, Siewers V, Nielsen J. Harnessing yeast peroxisomes for biosynthesis of fatty-acid-derived biofuels and chemicals with relieved side-pathway competition. J Am Chem Soc. 2016;138:15368-77.

21. Bourdenx B, Bernard A, Domergue F, Pascal S, Léger A, Roby D, Pervent M, Vile D, Haslam RP, Napier JA. Overexpression of Arabidopsis ECERIFERUM1 promotes wax very-long-chain alkane biosynthesis and influences plant response to biotic and abiotic stresses. Plant Physiol. 2011;156:29-45.

22. Coursolle D, Lian J, Shanklin J, Zhao H. Production of long chain alcohols and alkanes upon coexpression of an acyl-ACP reductase and aldehydedeformylating oxygenase with a bacterial type-l fatty acid synthase in $E$. coli. Mol BioSyst. 2015;11:2464-72.

23. Blazeck J, Garg R, Reed B, Alper HS. Controlling promoter strength and regulation in Saccharomyces cerevisiae using synthetic hybrid promoters. Biotechnol Bioeng. 2012;109:2884-95.

24. Hauf J, Zimmermann FK, Müller S. Simultaneous genomic overexpression of seven glycolytic enzymes in the yeast Saccharomyces cerevisiae. Enzyme Microb Technol. 2000;26:688-98.

25. Peng B, Plan MR, Carpenter A, Nielsen LK, Vickers CE. Coupling gene regulatory patterns to bioprocess conditions to optimize synthetic metabolic modules for improved sesquiterpene production in yeast. Biotechnol Biofuels. 2017:10:43.

26. Westfall PJ, Pitera DJ, Lenihan JR, Eng D, Woolard FX, Regentin R, Horning T, Tsuruta H, Melis DJ, Owens A, et al. Production of amorphadiene in yeast, and its conversion to dihydroartemisinic acid, precursor to the antimalarial agent artemisinin. Proc Natl Acad Sci. 2012;109:E111-8.

27. Howard RW, Blomquist GJ. Ecological, behavioral, and biochemical aspects of insect hydrocarbons. Annu Rev Entomol. 2005;50:371-93.

28. Samuels $L$, Kunst $L$, Jetter R. Sealing plant surfaces: cuticular wax formation by epidermal cells. Annu Rev Plant Biol. 2008;59:683-707.

29. Yu Z, Zhang X, Wang Y, Moussian B, Zhu KY, Li S, Ma E, Zhang J. LmCYP4G102: an oenocyte-specific cytochrome P450 gene required for cuticular waterproofing in the migratory locust, Locusta migratoria. Sci Rep. 2016;6:29980.

30. Chen N, Fan Y-L, Bai Y, Li X-D, Zhang Z-F, Liu T-X. Cytochrome P450 gene, CYP4G51, modulates hydrocarbon production in the pea aphid, Acyrthosiphon pisum. Insect Biochem Mol Biol. 2016;76:84-94.

31. Eser BE, Das D, Han J, Jones PR, Marsh EN. Oxygen-independent alkane formation by non-heme iron-dependent cyanobacterial aldehyde decarbonylase: investigation of kinetics and requirement for an external electron donor. Biochemistry. 2011;50:10743-50

32. Andre C, Kim SW, Yu XH, Shanklin J. Fusing catalase to an alkaneproducing enzyme maintains enzymatic activity by converting the inhibitory byproduct $\mathrm{H}_{2} \mathrm{O}_{2}$ to the cosubstrate $\mathrm{O}_{2}$. Proc Natl Acad Sci. 2013:110:3191-6. 
33. Khara B, Menon N, Levy C, Mansell D, Das D, Marsh ENG, Leys D, Scrutton NS. Production of propane and other short-chain alkanes by structurebased engineering of ligand specificity in aldehyde-deformylating oxygenase. Chembiochem. 2013;14:1204-8.

34. Smith SM. Strategies for the purification of membrane proteins. Methods Mol Biol. 2011;681:485-96.

35. Choi YJ, Lee SY. Microbial production of short-chain alkanes. Nature. 2013;502:571-4

36. Zhou YJ, Gao W, Rong Q, Jin G, Chu H, Liu W, Yang W, Zhu Z, Li G, Zhu G, et al. Modular pathway engineering of diterpenoid synthases and the mevalonic acid pathway for miltiradiene production. J Am Chem Soc. 2012;134:3234-41.
37. Agatep R, Kirkpatrick RD, Parchaliuk DL, Woods RA, Gietz RD. Transformation of Saccharomyces cerevisiae by the lithium acetate/single-stranded carrier DNA/polyethylene glycol protocol. Tech Tips Online. 1998;3:133-7.

38. Verduyn C, Postma E, Scheffers WA, Van Dijken JP. Effect of benzoic acid on metabolic fluxes in yeasts: a continuous-culture study on the regulation of respiration and alcoholic fermentation. Yeast. 1992;8:501-17.

39. Khoomrung S, Chumnanpuen P, Jansa-Ard S, Stahlman M, Nookaew I, Boren J, Nielsen J. Rapid quantification of yeast lipid using microwaveassisted total lipid extraction and HPLC-CAD. Anal Chem. 2013;85:4912-9.

\section{Submit your next manuscript to BioMed Central and we will help you at every step:}

- We accept pre-submission inquiries

- Our selector tool helps you to find the most relevant journal

- We provide round the clock customer support

- Convenient online submission

- Thorough peer review

- Inclusion in PubMed and all major indexing services

- Maximum visibility for your research

Submit your manuscript at www.biomedcentral com/submit 